Die Technik der Serumanwendung besteht in Injektionen. Was zunächst die Menge des einzuverleibenden Serums anlangt, so hat es sich gezeigt, daß große Dosen durchaus nicht größeren Effekt haben, ja im Gegenteil oft schlecht vertragen werden. Man injiziert also nur $5-10 \mathrm{ccm}$. Die Injektionen werden subkutan oder per rectum verabfolgt.

Ein Unterschied in der Wirkungsweise der verschiedenen Art der Einverleibung wird allgemein angenommen. Ganz abgesehen von den Erscheinungen der Anaphylaxie - den Wirkungen des artfremden Serums - bei subkutaner Darreichung, ist nicht zu leugnen, daß in manchen Fällen wenigstens ein schnelleres Auftreten der Serumwirkung auf den KrankheitsprozeB beobachtet werden konnte. Indes es hat sich gezeigt, daß die oben genannten

Aus der Chirurgischen Universitätspoliklinik der Charité in Berlin. (Direktor: Geh. Med.-Rat Prof. Dr. Hildebrand.)

\section{Die Anwendung und die Erfolge des Marmorek-Serums.}

\author{
(Sammelreferat.)
}

Vun Dr. Paul Glaessner, orthopädischer Assistent der Klinik.

Dank dem liebensw ürdigen Entgegenkommen meines Chefs, Herrn Prof. Dr. Pels-Le usden, bin ich seit kurzem in die angenehme Lage versetzt, das reiche Material unserer Poliklinik an Tuberkulösen mit Marmorekschem Antituberkuloseserum behandeln zu können. Da ist es mein erstes Bemühen gewesen, die große Literatur, die bisher über das Serum erschienen ist, gründlich durchzusehen.

Ein großes Stück Arbeit ist geleistet worden, aber wie es scheint, ist viel mehr noch zu tun. Die große Zahl der Publikationen - Frey konnte bis Juli 1908 schon 76 zusammenstellen, und seitdem ist eine weitere, recht stattliche Anzahl (16) erschienen spricht zunächst nur für das Interesse an einem neuen Mittel gegen die Tuberkulose, sie beweist nicht das Interesse für das Marmorekserum. Die kühle Zurückhaltung kommt selbst in vielen Arbeiten zum Vorschein, die über günstige Serumwirkungen $\mathrm{zu}$ berichten wissen, und nicht selten findet man die Zusammenfassung über die erzielten Resultate weniger günstig gefärbt, als die mitgeteilten Krankengeschichten erwarten lassen, ganz zu schweigen von merkwürdigen Entschuldigungen, das Serum trotz seiner anfechtbaren theoretischen Grundlagen angewendet zu haben etc. Bei der Durchsicht der Literatur begegnet man hier und da auch solchen Mitteilungen, wo auf Grund weniger Beobachtungen an ganz schweren Tuberkulosen mit fehlendem oder negativem Befund über das Serum kurzweg der Stab gebrochen wird und neue Versuche als aussichtslos aufgegeben werden. Auch die völlige Unkenntnis der Wirkung artfremden Serums (Anaphylaxie) hat die Anwendung des Marmorekserums beträchtlich beeinträchtigt.

Man hat gewiß keine Ursache, einem neu erscheinenden Heilmittel gegen die Tuberkulose begeistert zuzujubeln, die Hoffnungen sind schon zu schwer enttäuscht worden. Aber angesichts unserer A rmut an wirksamen spezifischen Mitteln hat man doch die Verpflichtung, neue Heilfaktoren einer gründlichen und gewissenhaften Nachprüfung an einem möglichst großen Material zu unterziehen, und das besonders dann, wenn sich diese Heilfaktoren als vollständig unschädlich erwiesen haben. Eine solche Prüfung unter Kontrolle von Gipsabgüssen, Röntgenbildern, Zeichnungen und Photographien anzustellen, bin ich eben im Begriffe und behalte mir vor, die erreichten Resultate seinerzeit in extenso mitzuteilen.

Heute möchte ich mir nur gestatten, über das Urteil zu berichten, das gegenwärtig über das $\mathrm{M}$ a rmorekserum gefällt wird, und über die jüngsten Arbeiten, die sich mit dem Marmorekserum befassen.

Aus dem oben zitierten Sammelreferat von Frey (Davos) geht hervor, daß von 70 Arbeiten nur elf $\mathrm{zu}$ einem ablehnenden Urteil gekommen sind und 833 mit positivem Erfolg behandelten Fällen 105 mit negativem Erfolg gegenüberstehen. Das allein zeigt schon dentlich, daß dem Serum ein Heilwert innewohnen muß. Aber selbst wenn man diese Zahlen nicht gelten lassen will - Frey hebt selbst hervor, daß man bisweilen bei der Unzulänglichkeit der Krankengeschichten aus diesen oft gegen die Absicht des Autors "verschiedenes" herauslesen kann - so spricht doch die große Zahl der Beobachter deutlich dafür, daß eine Täuschung nicht mehr mög lich ist; ein paarmal könnte wohl „danach“ für "deswegen " genommen werden, aber bei so vielen und so verschiedenen Beobachtern, bis jetzt sind 1229 Fälle beobachtet und beschrieben worden, scheint dies doch ausgeschlossen.

Die Ursachen für die erfolglose Anwendung des Serums in manche Fällen sind uns noch gänzlich unbekannit, soweit es sich nicht um Fälle handelt, die man von vornherein von der Serumbehandlung ausschließen sollte. Oder glaubte man sich wirklich von der Einwirkung eines Serums das Wunder versprechen zu können, alte, schwerste, multiple anatomische Veränderungen durch subkutane oder intrarektale Injektionen zur Ausheilung zu bringen?
Erscheinungen vielfach eine recht unangenehme Zugabe der Serumwirkung darstellen, soda $B$ man schlieBlich ziemlich allgemein zu der rektalen Methode der Serumapplikation übergegangen ist. Man hat nun gewisse Schemata aufgestellt, wie häufig die Injektionen vorgenommen werden sollen, und hat im allgemeinen es für gut befunden, 8 bis 10 Tage hindurch zu injizieren, dann je nach dem Befinden und dem Krankheitszustand des Patienten eine 8 bis 10 bis 14 tägige Pause für die Injektionen eintreten zu lassen. DaB auch hier ein strenges Individualisieren wertvoller ist als eine Menge Schemata, bedarf keines besonderen Hinweises.

Die zur subkutanen Injektion benutzte Menge soll $5 \mathrm{ccm}$ nicht übersteigen; zur rektalen Einverleibung kann man 10, bisweilen noch mehr Kubikzentimeter nehmen. Während man bei den rektalen Injektionen nur selten irgendwelche Ursache hat, den Turnus der Einspritzungen zu unterbrechen - nur vereinzelt treten leichte Durchfälle auf, die nach wenigen Tagen wieder verschwinden sind die lokalen und allgemeinen Reaktionen artfremden Serums bei der subkutanen Injektion bisweilen so schwere, daB man sie genau kennen muß, um nicht in große Sorge um seine Patienten zu geraten. Leichte Rötungen und Schwellungen lokaler Natur in der Umgebung der Injektionsstellen - Bauch-, Brust- und Rückenhaut - mit geringen Temperatursteigerungen kommen da weniger in Betracht als das mit hohem Fieber, schwer gestörtem Allgemeinbefinden, Appetitlosigkeit und Stuhlverstopfung einhergehende urticariaähnliche Serumexanthem mit seinem bisweilen ganz unerträglichen Juckreiz. Den Kundigen schreckt dieser Zustand nicht, so unangenehm er auch momentan für den Patienten und den Arzt sein mag, denn ohne jede weitere Störung erfolgt vollkommene $\mathrm{Ge}$ nesung, der Kranke fühlt sich nach wenigen Tagen außerordentlich wohl, hat großen Appetit bekommen, und der lokale Prozeß zeigt oftmals eine erhebliche Besserung.

Immerhin sind die geschilderten Erscheinungen für manchen unangenehm und erschweren besonders dort, wo nicht ständige Ueberwachung der Patienten möglich ist, die Anwendung bisweilen ganz erheblich. Es muß hervorgehoben werden, daß durchaus nicht alle Patienten in der geschilderten Weise auf die subkutanen Injektionen reagieren und daß man bei einiger Kenntnis der Anaphylaxie, besonders der leichteren Prodrome, die schweren Symptome derselben unschwer ganz vermeiden kann.

All diesen Unannehmlichkeiten geht die Methode der rektalen Einverleibung des Serums aus dem Wege. Sie gestattet, die $\mathrm{Be}-$ handlung auch ambulant außerhalb der Klinik durchzuführen, und läßt so gut wie nie stärkere Nebenwirkungen erkennen. Es braucht wohl nicht besonders betont zu werden, daß man darauf achten muß, daß das Serum nicht sofort aus dem Rectum wieder entleert wird.

Was nun die Wirkungen anlangt, so muß die Mehrzahl der bisher vorliegenden Berichte mit etwas Vorsicht aufgenommen werden. Frey konnte im ganzen 938 behandelte Fälle zusammenstellen, denen ich aus den mir zugänglichen neueren Arbeiten noch 138 anfügen kann. Von diesen sind $67 \%$ günstig durch das Serum beeinfluBt resp. geheilt worden, während $33 \%$ unbeeinfluBt blieben, sich verschlechterten oder gestorben sind. Wenn diese Zahlen sich auch in Zukunft so günstig gestalten, so hätten wir an dem Serum gewiß ein außerordentlich wertvolles Heilmittel gewonnen, denn zwei Drittel unserer Tuberkulosen würde es bessern oder heilen! Aber ich halte für so weitgehende Schlüsse die Zahlen noch für viel zu klein und das Material noch für viel zu wenig einheitlich. Die Zahl der behandelten chirurgischen Tuberkulosen beträgt nach Frey nur 239 mit $79 \%$ Heilungen und Besserungen. Aus dieser geringen Zahl von Fällen kann man noch keine bindenden Schlüsse ziehen. $A$ ber auch aus der beinahe dreimal so großen der behandelten Fulle von Lungen- und Kehlkopftuberkulose läßt sich noch kein Resultat ableiten, schon deshalb, weil darunter eine ganze Reihe von Fällen sich befindet, die schon die ganze Kette der Behandlungsmethoden durchgemacht haben und bei denen nichts mehr zu verlieren, aber nach menschlicher Voraussicht auch kaum mehr etwas zu gewinnen war.

Am meisten und am schnellsten lassen sich die Wirkungen des Serums an frischen Fällen von Tuberkulose erkennen, und ich kann mich nach meinen Beobachtungen auch an einer früheren Versuchs- 
serie gewiß den Mitteilungen anderer anschließen, daß ganz ab. gesehen ron den auffallend schnell eintretenden Besserungen in Stimmung, Allgemeinbefinden, Appetit, es geradezu wunderbar ist, wie schon nach wenigen Injektionen alte, monatelange bestehende Fisteln mit starker Sekretion auffallend geringe Absonderung zeigen, wie Schwellungen und Geschwürsbildungen zurückgehen etc. Aber davon soll später anderweitig ausführlich berichtet werden. Das groBe Sammelreferat von Frey ${ }^{1}$ ) enthält alle Literaturangaben mit den Urteilen der einzelnen Autoren über das Serum in übersichtlicher Weise zusammengestellt. Es hieße demnach nur Mitgeteiltes wiederholen; wollte ich nochmals über alle diese Arbeiten in extenso berichten.

In der letzten Zeit sind nun noch mehrere Arbeiten erschienen, welche die Wirkung des Marmorek serums ausführlicher behandeln. Die Arbeit von Strauss') bringt die Erfahrungen, welche bei der Serumbehandlung von 38 Fällen an der Greifswalder Klinik gemacht worden sind. Von sieben schweren Fällen - bei drei derselben konnte der Autor selbst nach seiner Angabe eine Heilung nicht mehr erwarten - wurden $z$ wei Fälle gebessert und einer gänzlich geheilt, von 18 mittelschweren Fällen wurden acht geheilt, acht fast geheilt oder gebessert, zwei blieben ungeheilt, während von den zehn leichten Fällen alle geheilt oder gebessert wurden. Bei der sachlichen strengen Kritik des Autors bedürfen diese Zahlen weiter keines Kommentars und sprechen genügend für den Wert des Serums. Die vorsichtigen Schlußfolgerungen, die Strauss aus seiner Arbeit zieht, dürften in Zukunft erweitert werden können.

Ueber 17 Fälle von chirurgischer Tuberkulose, die mit Marmor ek serum behandelt worden sind, berichtet Sickemeier ${ }^{8}$ ). Davon wurden 6 geheilt, 6 wesentlich gebessert, 5 blieben unbeeinflußt. Alle Fälle waren vorher ein halbes Jahr beobachtet und ohne Erfolg mit anderen Methoden behandelt worden. Ferner ist eine Arbeit von Grimer) zu erwähnen, welche sich mit Impf- und Injektionsversuchen mit Gemengen von Tuberkulin und Marmorekserum befaßt. Grimer konnte weder bei Lungen- noch bei Knochentuberkulose der Rinder eine zuverlässige Heilwirkung erkennen. Selbst das Auftreten neuer Krankheitsherde konnte bei Serumanwendung beobachtet werden. Sein Urteil ist im allgemeinen $a b$ sprechend. Ich selbst ${ }^{5}$ ) habe über 10 Fälle berichtet, von denen 8 eine deutlich günstige Serumwirkung erkennen ließen und $2-$ 1 Fall gehörte zu den allerschwersten multiplen Tuberkulosen unbeeinflußt blieben. Die Beobachtungen Köhlers ${ }^{8}$ ) von $60 \mathrm{Tu}$ berkulosefällen ließen den Autor von einer zuverlässigen Wirkung nicht sprechen. Ueber günstige Erfahrungen ohne bindende Schlüsse können auch Sokolowski und Dembinsky berichten, ${ }^{7}$ ) sowie eine Arbeit von Freiberg, günstigen Schlußfolgerungen kommt.

Schließlich ist noch eine Arbeit von van Huellen zu nennen,") welcher 3 besonders prägnante Fälle mit ausgezeichneten Erfolgen mitteilt. Der Autor verwendet lieber die subkutane Injektion, weil er sich von derselben eine größere Wirkung verspricht, injiziert aber dort, wo die oben angeführten Indikationen vorliegen, das Serum auch per rectum.

Aus all dem geht hervor, daß, einige Beobachtungen ausgenommen, auch in jüngster Zeit recht erhebliche Erfolge bei der Behandlung speziell der chirurgischen Tuberkulose mit dem Marmorekschen Antituberkuloseserum erzielt worden sind. Noch scheint das beobachtete Material zu klein und zu wenig einheitlich und die Zeit der Einzelbeobachtungen zu kurz, als daß sich ein definitives Urteil über die allgemeine Bedeutnng des Marmorekserums für die Therapie der Tuberkulose abgeben ließe. Aber soviel steht heute schon fest: nach den bisher an einer großen Zahl von Fällen beobachteten spezifischen und günstigen Einwirkungen des Marmorekserums ist man bei der völligen Unschädlichkeit des Mittels zu weiteren ausgedehnten Versuchen nicht nur berechtigt, sondern auch verpflichtet. Erst ausgedehnte klinische Erfahrung wird Aufschluß über die beste Technik seiner Anwendung und die Grenzen seiner spezifischen Heilkraft geben.

Anmerkung bei der Korrektur: Seit der Abfassung des obigen Sammelreferats (Dezember 1908) ist noch eine Reihe von Arbeiten über das Marmorekserum erschienen, die über sehr gute Erfahrungen zu berichten wissen, so von Schenker, Monod, Freiberg, Clement und Jacobson sowie von Wein. Eine eingehende Besprechung der in diesen Arbeiten niedergelegten Beobachtungen soll erfolgen, sobald ich meine eigenen Untersuchungsreihen abgeschlossen habe.

1) Zeitschrift für Tuberkulose, Bd, 13, H. 2, - 2) Münchener medizinische

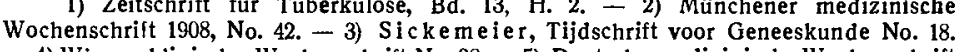
- 4) Wiener klinische Wochenschrift No.38. - 5) Deutsche medizinische Wochenschrift No. 29. - 6) Deutsche medizinische Wochenschrift No. 29. - 7) Zeitschrift für Tuberkulose, Bd. 13, H. 2. u. 3. - 8) Amer. Journ. of orthop. Surgery, August 1908. - 9) Deutsche Zeitschrift für Chirurgie, Bd 95. 